\title{
Mapping of Lineaments and Knowledge Base Preparation using Geomatics Techniques for part of the Godavari and Tapi Basins, India: A Case Study
}

\author{
A. D. Prasad \\ Indian Institute of Technology \\ Roorkee \\ Roorkee-247667, India
}

\author{
Kamal Jain \\ Indian Institute of Technology \\ Roorkee \\ Roorkee-247667, India
}

\author{
Ajay Gairola \\ Indian Institute of Technology \\ Roorkee \\ Roorkee-247667, India
}

\begin{abstract}
Earth consists of hard rock layers where water is restricted to secondary permeability, and thus to fractures and the weather zones. Structural geology studies, geologic lineaments and their pattern information are essential for better planning and execution of projects to avoid any natural hazards. Satellite images, aerial photographs and digital elevation models will give lineament information. Recent advances in digital image processing allow such lineament extraction to be accomplished in semi-automatic to fully automatic approaches. The accuracy of extracting lineaments depends strongly on the spatial resolution of the imagery, higher resolution imagery result in a higher quality of lineament map. In this paper, an attempt has been made for Mapping of lineaments and knowledge base preparation using geomatics techniques for part of the Godavari and Tapi Basins, India. A methodology for lineament extraction and the design of a knowledge-based lineament identification system has been proposed for geological aspects of any developmental activity. This methodology might potentially be adopted for the identification of several features of geological or anthropogenic origin. The study results of lineaments and the rose diagrams of the extracted lineaments can be applied to structural geology studies and their applications such as oreforming systems, mineral exploration, petroleum, nuclear energy facility sittings and water resource investigations, groundwater studies and also for finding suitable sites for dams and reservoirs.
\end{abstract}

\section{General Terms}

GIS, Knowledgebase.

\section{Keywords}

Lineaments, DEM.

\section{INTRODUCTION}

Satellite data are very useful in various applications, like astronomy, atmospheric studies, earth observation, communications, navigation, search and rescue. Satellite images, aerial photographs and digital elevation models (DEM) will give lineament information (26, 28). The identified line features in satellite images, aerial photographs and DEM's may represent natural morphological alignments or those of anthropogenic nature (roads, aqueducts, crops, etc.). Structural discontinuities of rocks and other features related to tectonic activity often results in morphological lineaments (fault scarps, joints, fold axis, etc.; (30). These lineaments can be expressed as linear valleys, linear slope breaks or linear ridgelines (14).

Hobbs introduced lineament into geology and discussed lineament patterns $(7,8)$. Geologic lineament mapping is considered as a very important issue for problem solving in engineering, especially, in site selection for construction (dams, bridges, roads, etc), seismic and landslide risk assessment (36), mineral exploration (32), hot spring detection, hydrogeological research, etc. $(33,34)$.

Lineament identification using geomatics techniques can be achieved by image enhancement techniques (image ration, image fusion, directional edge-detection filters) and a lineament vector map can be produced using manual digitizing techniques $(1,38)$. Second, a lineament map may be produced using computer software and algorithms $(3,15,2$, $10,11,17)$

A comparison between the visual and automatic methods for lineament extraction is shown in Table 1.

Furthermore, edge extraction is not adequate for performing identification of geologic linear features, as they do not consider the inherent geologic information into account. Expert systems (12) and other knowledge-based systems (13) were implemented to overcome problems addressed by edge extraction. The main drawback of these systems was their inefficiency to visualize the identified lineaments in a unified graphical environment.

The study of lineaments has been applied successfully to structural geology studies and their applications such as oreforming systems, mineral exploration, petroleum, nuclear energy facility sittings $(19,40,41,25,18,15,24,1,38,42)$, water resource investigations, groundwater studies $(20,21$, $22,6,11$ ), hazard assessment (4) and geological and other studies $(37,23,35)$.

In this paper, an attempt has been made for mapping of lineaments and knowledge base preparation using geomatics techniques for part of the Godavari and Tapi Basins, India. 
Table 1. Comparison between the visual and automatic methods for lineament extraction

\begin{tabular}{|l|l|}
\hline Visual Inspection and Extraction Process & Digital Analysis and Automatic Extraction Process \\
\hline $\begin{array}{l}\text { Highly depends on the quality of the image and its } \\
\text { printed hardcopy (soft copy and hard copy) }\end{array}$ & Highly depends only on the image quality (soft copy) \\
\hline Partially depends on the complexity of research area & $\begin{array}{l}\text { Completely depends on the complexity of research } \\
\text { area }\end{array}$ \\
\hline Time taking process and expensive & $\begin{array}{l}\text { Consumes very less time and cheap when compared to } \\
\text { visual process }\end{array}$ \\
\hline $\begin{array}{l}\text { Efficiency depends on a person's knowledge, skill and } \\
\text { experience }\end{array}$ & Efficiency depends on software and process used \\
\hline Type of lineaments can be distinguished easily & $\begin{array}{l}\text { Distinguishing type of lineaments may be complex as } \\
\text { it includes anthropogenic alignments }\end{array}$ \\
\hline Simple but subjective method & Complex but objective method \\
\hline
\end{tabular}

\section{STUDY AREA}

All The study area is a part of the Godavari and Tapi Basins in the state of Maharashtra, India in between $17^{\circ} 0^{\prime} 0{ }^{\prime \prime}-19^{\circ} 0^{\prime} 0$ ' $\mathrm{N}$ and $73^{\circ} 0^{\prime} 0^{\prime \prime}-74^{\circ} 0^{\prime} 0$ " E (Figure 1) and covers a total area of about $34,225 \mathrm{~km}^{2}$.

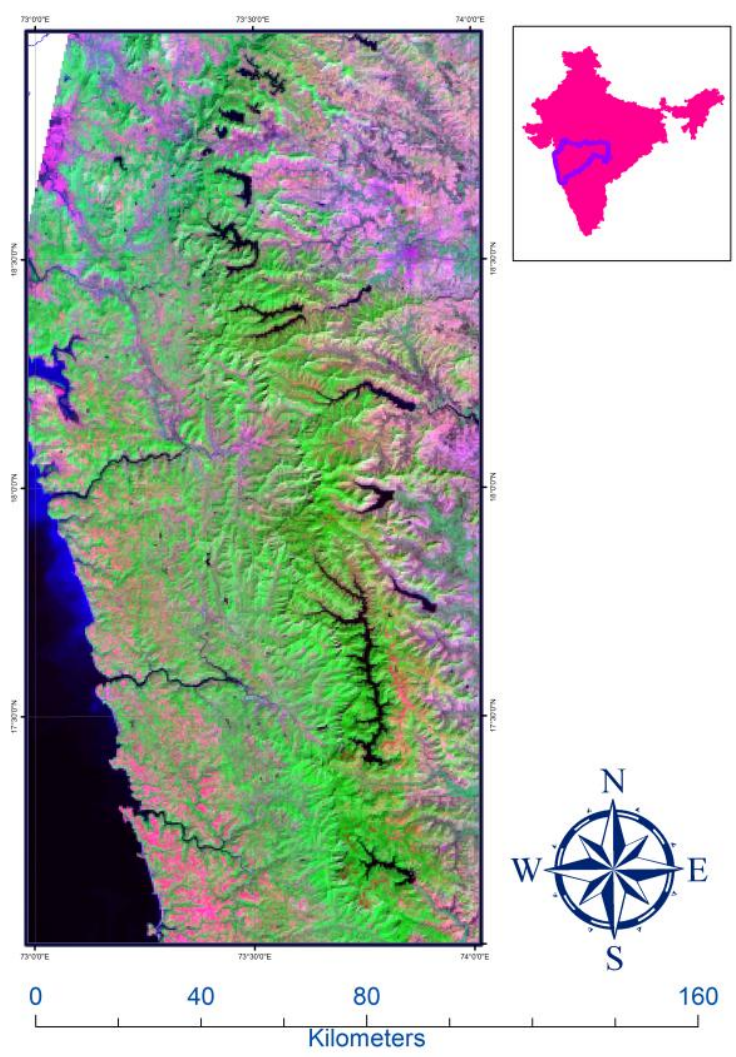

Figure 1. Study Area

The elevation in the region varies between $0-1,435 \mathrm{~m}$. The Godavari is a perennial and the second largest river draining in India originates near Trayambak near Nasik, northeast of Mumbai in the state of Maharashtra at an elevation of 1067 mamsl (meters above mean sea level) and flows for a long of about $1465 \mathrm{~km}$ before joining the Bay of Bengal. The Tapi River rises near Multai town in Betul district of Madhya
Pradesh at an elevation of about 760 mamsl and flows for a length of about $724 \mathrm{~km}$ before joining the Arabian Sea near Surat in Gujarat.

The study area receives the major part of its rainfall during the Southwest monsoon period. Daily, monthly and annual rainfall in the basin has been analyzed from India Meteorological Department (IMD) data. It is found that rainfall varies temporally and spatially across the study area. More than $85 \%$ of the rainfall takes place during July to September months and annual rainfall in the area varies from $881 \mathrm{~mm}$ to $1,395 \mathrm{~mm}$ and average annual rainfall is found to be $1,110 \mathrm{~mm}$. When spatial variables are considered, some areas receive $600 \mathrm{~mm}$ and some other areas receive $3000 \mathrm{~mm}$ annual rainfall.

Temperature in the study area has a range of Max. 39-43 to Min. 15-20, Humidity Max.82-87\% to Min. $12-31 \%$. Temperature variation in a year causes a lot of monthly variations in the potential evapotranspiration in the area. Minimum potential evapotranspiration in the area is 30 to 100 $\mathrm{mm}$ during January/February and maximum goes up to 400 $\mathrm{mm}$ to $450 \mathrm{~mm}$ during April/May months.

Theexistingdam in theregioniskoyna on the river koyna with storage capacity of $2,797,400 \mathrm{~km}^{3}$ and surface area of 11,535 $\mathrm{km}^{2}$. The purpose of the dam is mainly hydro electricity.

\section{MATERIALS AND METHODS}

DEM from the Advanced Spaceborne Thermal Emission and Reflection Radiometer (ASTER) of study area tiles "N17E73" and "N18E73" of $30 \mathrm{~m}$ resolution were used as input for mapping of lineaments and knowledge base preparation using geomatics techniques for part of the Godavari and Tapi Basins, India.(Figure 2).

The methodology in this study has been divided into four phases as follows and detailed as below: (1) Data Preparation, (2) Data Processing, (3) Extraction of lineaments, (4) Design of knowledge base system.

\subsection{Data Preparation}

Making a good mosaic requires some planning as their order can help to decide which images should overlay others. ArcGIS's data management tools are used to make a mosaic data set to cover study area. 


\subsection{Data Processing}

The data has been processed / prepared as appropriate thematic maps for their direct / indirect introduction to the knowledge base lineament identification expert system. The derived thematic data is supporting to the mapping / extraction / identification of lineaments and lineament types.

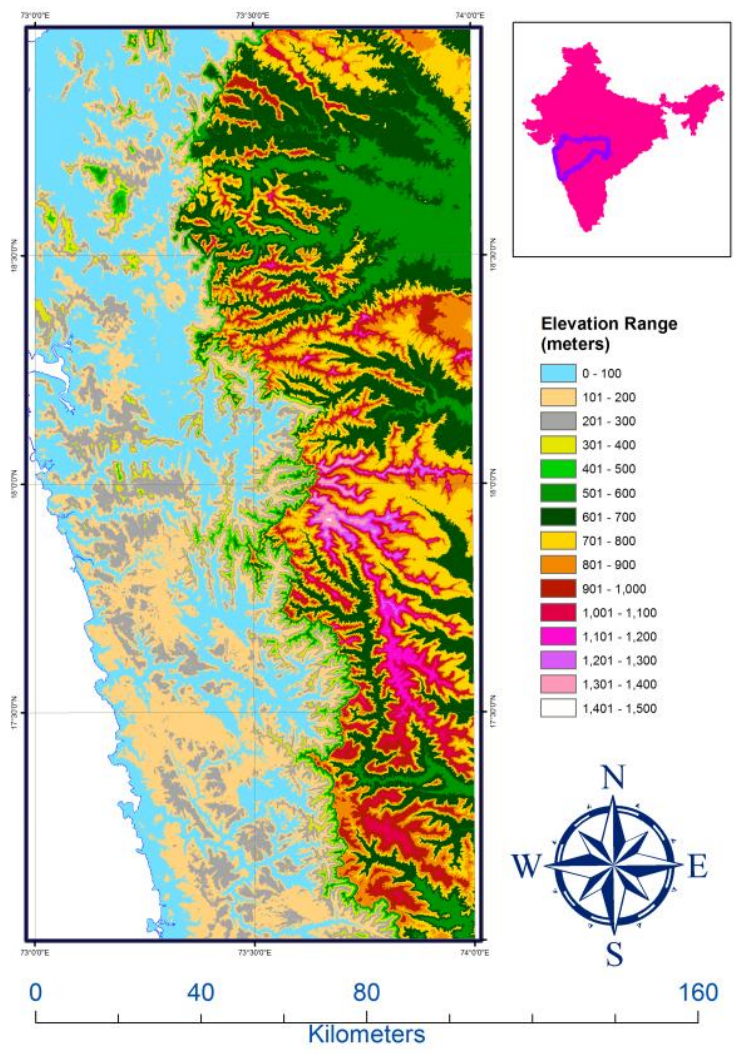

Figure 2. Digital Elevation Model (DEM)

\subsection{Extraction of Lineaments}

As discussed, there are two common methods for the extraction of lineaments from satellite images:

$>$ Visual extraction: At which the user first starts with some image processing techniques to make edge enhancements, using the directional and non-directional filters such as the Laplacian, and Sobel, then the lineaments are digitized manually by the user.

$>$ Automatic extraction: various computer-aided methods for lineament extraction have been proposed. Most methods are based on edge filtering techniques. The most widely used software for the automatic lineament extraction are ERDAS, ENVI and PCI Geomatica.

In this study, PCI Geomatica software has been used for digital analysis and automatic extraction process. The algorithm parameters used for processing are as follows:

- $\quad$ RADI - Radius of filter in pixels

- GTHR - Threshold for edge gradient

- $\quad$ LTHR - Threshold for curve length

- FTHR - Threshold for line fitting error

- ATHR - Threshold for angular difference

- DTHR - Threshold for linking distance

The algorithm consists of three stages (PCI Geomatica Manual, 2013):
- $\quad$ Edge Detection

- Thresholding

- Curve Extraction

In the first stage, the Canny edge detection algorithm is applied to produce an edge strength image. The Canny edge detection algorithm has three sub steps. First, the input image is filtered with a Gaussian function whose radius is provided by the RADI (Filter Radius) parameter. Then, the gradient is computed from the filtered image. Finally, pixels whose gradient are not the local maximum are suppressed by setting the edge strength to 0 .

In the second stage, the edge strength image is thresholded to obtain a binary image. Each ON pixel of the binary image represents an edge element. The threshold value is defined by the GTHR (Edge Gradient Threshold) parameter.

In the third stage, curves are extracted from the binary edge image. This step consists of several sub steps. First, a thinning algorithm is applied to the binary edge image to produce pixel-wide skeleton curves. Then, a sequence of pixels for each curve is extracted from the image. Any curve with a number of pixels less than the value of the LTHR (Curve Length Threshold) parameter is discarded from further processing. An extracted pixel curve is converted to vector form by fitting line segments to it. The resulting polyline is an approximation of the original pixel curve, where the maximum fitting error (distance between the two) is specified by the FTHR (Line Fitting Threshold) parameter. Finally, the algorithm links pairs of polylines that satisfy the following criteria:

$>$ Two end-segments of the two polylines face each other and have similar orientation (the angle between the two segments is less than the value specified by ATHR)

$>$ The two end-segments are close to each other (the distance between the end points is less than the value of DTHR)

The final polylines are saved in a vector segment.

Using above algorithm, the database has been generated for the parameter sets shown in Table 2 .

Table 2. Parameter sets for database generation

\begin{tabular}{|c|c|c|c|c|}
\hline Parameter & C1 & C2 & C3 & O \\
\hline RADI & 12 & 5 & 5 & 5 \\
\hline GTHR & 90 & 10 & 10 & 60 \\
\hline LTHR & 30 & 7 & 3 & 30 \\
\hline FTHR & 10 & 3 & 3 & 2 \\
\hline ATHR & 30 & 7 & 7 & 20 \\
\hline DTHR & 20 & 3 & 3 & 1 \\
\hline
\end{tabular}

\subsection{Design of knowledge based system}

The design of a knowledge-based system that could identify and categorize the geologic and topographic lineaments from the intersecting and non-interest linear segments database generated from automatic process, visual inspection of imageries, toposheets and other related information like slope, aspect, roads etc. 
The various procedural stages involved in this knowledgebase system are as follows:

- To form an idea about lineament mapping / extraction / identification

- Knowledge acquisition based on the inherent characteristics of the study area

- Knowledge acquired by the geo-data and derived thematic data supporting to the mapping / extraction / identification of lineaments and lineament types

- Knowledgebase of lineaments extracted / identified for various parameter groups

- Data analysis in multi-scale segmentation

- Knowledge representation using query / fuzzy rules.

\section{RESULTS}

Knowledge acquired by the geo-data and derived thematic data supporting to the mapping / extraction / identification of lineaments and lineament types has been shown in Figure 3.

Analysis has been done on the data and the data set "O" is most reliable than data set $\mathrm{C} 1$ than data set $\mathrm{C} 2$ than data set $\mathrm{C} 3$. The reasons may be as follows: For data set "O", the RADI parameter chosen is 5 . Because higher values of RADI results in loss of data and joining of lines. For the GTHR parameter lower than the determined region gives plenty of lineaments that appear to be non-geologic. Also values higher than the region yields to poor results with respect to the output number and total length. Hence value 60 was chosen for balance. The LTHR value must not be higher than the region in order not to obtain circular shapes. Below the lower value curvilinear lineaments are eliminated. Hence value 30 was chosen for balance. FTHR parameter chosen as 2 in order to get shorter line segments that better approximate the lineament.The ATHR parameter chosen as 20. By visual inspection, it is found that the ATHR value less than 20 processes disconnected lines while ATHR value higher than 20 processes in polygon shaped lines. The DTHR value determines the maximum distance of two lineaments to be linked. To detect discontinuity sets with high resolution data, it is better to detect lineaments separately. Hence, minimum value of 1 is chosen. The generated database with parameter sets are presented in Figure 4.

Results of the data base generation using parameter sets are shown in the Table 3.

Table 3. Data base details of parameter sets

\begin{tabular}{|c|c|c|c|c|}
\hline $\begin{array}{c}\text { Database } \\
\text { of }\end{array}$ & $\begin{array}{c}\text { Number } \\
\text { of } \\
\text { Lineaments }\end{array}$ & $\begin{array}{c}\text { Max } \\
\text { Length } \\
(\mathbf{m})\end{array}$ & $\begin{array}{c}\text { Min } \\
\text { Length } \\
(\mathbf{m})\end{array}$ & $\begin{array}{c}\text { Avg } \\
\text { Length } \\
(\mathbf{m})\end{array}$ \\
\hline $\mathrm{C} 1$ & 131 & 5227 & 880 & 1497 \\
\hline $\mathrm{C} 2$ & 12078 & 2785 & 206 & 449 \\
\hline $\mathrm{C} 3$ & 16435 & 2785 & 88 & 364 \\
\hline $\mathrm{O}$ & 3 & 1774 & 900 & 1437 \\
\hline
\end{tabular}

Directional analysis of the lineaments has been done by rose diagrams and results are presented in Figure 5.

\section{CONCLUSION}

In this paper, an attempt has been made for Mapping of lineaments and knowledgebase preparation using geomatics techniques and expert systems for part of the Godavari and Tapi Basins, India. A methodology for lineament extraction and the design of a knowledge-based lineament identification system provides quite satisfactory results for geological aspects of any developmental activity. Due to its multi-scale feature detection and representation ability, this methodology might potentially be adopted for the identification of several features of geological or anthropogenic origin. The study results of lineaments and the rose diagrams of the extracted lineaments can be applied to structural geology studies and their applications such as ore- forming systems, mineral exploration, petroleum, nuclear energy facility sittings and water resource investigations, groundwater studies and also for finding suitable sites for dams and reservoirs.

\section{ACKNOWLEDGMENTS}

Our thanks to the experts who have contributed towards improvement of the paper.We would like to thank ASTER for providing DEM free of cost.

\section{REFERENCES}

[1] Arlegui, L. E., Soriano, M. A., "Characterizing lineaments from satellite images and field studies in the central Ebro basin (NE Spain)", International Journal of Remote Sensing 19 (16), 3169-3185, 1998.

[2] Baumgartner, A., Steger, C. Mayer, Eckstein, W. and Ebner, H., "Automatic road extraction based on multiscale grouping and context", Photogrametric Engineering and Remote Sensing, Vol. 65, PP. 777-785, 1999.

[3] Burdick, R. G. and Speirer, R. A., "Development of a method to detect geologic faults and other linear features from LANDSAT images", U. S. Bureau of Mines Report Inv., 8413:74, 1980.

[4] David M. TralliT, Ronald G. Blom, Victor Zlotnicki, Andrea Donnellan, Diane L. Evans: "Satellite remote sensing of earthquake, volcano, flood, landslide and coastal inundation hazards", ISPRS Journal of Photogrammetry \& Remote Sensing 59: 185- 198, 2005

[5] Extraction of morphotectonic features from DEMs: Development and applications for study areas in Hungary and NW Greece. International Journal of Applied Earth Observation and Geoinformation, 7: 163-182.

[6] Fernandes, A.J., Rudolph, D.L., "The influence of Cenozoic tectonics on the groundwater production capacity of fractured zones: a case study in Sao Paulo, Brazil”, Hydrogeology Journal 9, 151-167, 2001

[7] Hobbs, W.H., "Earth Features and Their Meaning: An Introduction to Geology for the Student and General Reader", Macmillan, New York, NY (347pp), 1912.

[8] Hobbs, W.H., "Lineaments of the Atlantic border region", Geological Society of America Bulletin 15, 483-506, 1904.

[9] Hung L.Q, Batelaan O, and De Smedt F: "Lineament extraction and analysis, comparison of LANDSAT ETM and ASTER imagery. Case study: Suoimuoi tropical karst catchment, Vietnam". Remote Sensing for Environmental Monitoring, GIS Applications, and Geology V, edited by Manfred Ehlers, Ulrich Michel, Proc. of SPIE Vol. 5983, 59830T, 2005

[10] Hung LQ, Dinh NQ, Batelaan O, Tam VT, Lagrou D, "Remote sensing and GIS-based analysis of cave development in the Suoimuoi catchment (Son La-NW Vietnam)", Journal of Cave and Karst Studies 64(1):2333, 2002. 
[11] Hung, L.Q. and Batelaan, O., "Environmental geological remote sensing and GIS analysis of tropical karst areas in Vietnam", Proceedings of the IEEE International Geoscience and Remote Sensing Symposium (IGARSS), Toulouse, France, 21-25 July 2003, Volume IV, p. 29642966, 2003

[12] Iasuda, Sh.. Tokuo, T., Ichinose, Ts., Otani, K. and Uchi, T.: "Expert System for Lineament Extraction from Optical Sensor Data". Geoinformaties, 2, 195-200. 1991

[13] Iorris K.: "Using kiowledge-base rules to map the threedimensional nature of geological features". PhotogrammetricEng. and Rem. Sens.. 57. 1209-1216, 1991

[14] Jordan. G., Meijninger. B.M.L.. Hinsbergen. D.J.J.v., Meulenkamp. J.E. and Dijk. P.M.v.. 2005.

[15] Karnieli, A., Meisels, A., Fisher, L., Arkin, Y., "Automatic extraction of geological linear features from digital remote sensing data using a Hough Transform", Photogrammetric Engineering \& Remote Sensing, 62, 525-531, 1996.

[16] Karnieli, A., Meisels, A., Fisher, L., Arkin, Y., "Automatic extraction of geological linear features from digital remote sensing data using a Hough Transform", Photogrammetric Engineering \& Remote Sensing, 62, 525-531, 1996.

[17] Kim, G.B., Lee, J.Y., Lee, K. K., "Construction of lineament maps related to groundwater occurrence with ArcView and AvenueTM scripts", Computers \& Geosciences, Vol. 30, 1117-1126, 2004

[18] Kutina, J., "Are lineaments ineffective guides to ore deposits?", Global Tectonics and Metallogeny, 1, p. 200205, 1980

[19] Lalor, J. H., "The Olympic Dam copper-uranium-gold deposit, South Australia". Transactions Fourth CircumPacific Energy and Mineral Resources Conference, Singapore. - American Association Petroleum Geologists. Tulsa, Oklahoma: 561-567, 1986

[20] Lattman, L.H., Parizek, R.R., "Relationship between fracture traces and the occurrence of ground water in carbonate rocks", Journal of Hydrology 2, 73-91, 1964.

[21] Mabee, S.B., Hardcastle, K.C., Wise, D.U., "A method of collecting and analyzing lineaments for regional-scale fractured-bedrock aquifer studies", Ground Water 32 (6), 884-894, 1994

[22] Magowe, M., Carr, J.R., "Relationship between lineaments and ground water occurrence in western Botswana", Ground Water 37 (2), 282-286, 1999

[23] Mazlan Hashim, Samsudin Ahmad, Mohd Amin Md Johari, Amin Beiranvand Pour:" Automatic lineament extraction in a heavily vegetated region using Landsat Enhanced Thematic Mapper (ETM+) imagery", Advances in Space Research 51: 874-890, 2013

[24] Mostafa, M., Zakir, F., "New enhanced techniques for azimuthal analysis of lineaments for detecting tectonic trends in and around the Afro-Arabian Shield", International Journal of Remote Sensing, 17, 2923-2943, 1996

[25] O'Driscoll, E. S. T. \& Campbell, I. B., "Mineral deposits related to Australian continental ring and rift structures with some terrestrial and planetary analogies. Global Tectonics and Metallogeny 6: 83-101, 1997
[26] Oilier. C.D.. 1981. Tectonics and landforms. Geomoiphology texts, 6. Longman Group Limited, New York, 324 pp.

[27] Pacific Energy and Mineral Resources Conference, Singapore. - American Association Petroleum Geologists. Tulsa, Oklahoma: 561-567, 1986,

[28] Panizza. M.. Castaldini. D., Bolletlinari. G.. Carton. A. and Mantovani. F., 1987. Neotectonic research in applied geomorphological studies. Zeitschrift für Geomorphologie, 63: 173-21 1.

[29] PCI Geomatica Manual, 2013

[30] Ramsay. J. and Htiber. M., 1987. The techniques of modern structural geology. Volume 2: folds and fractures. Academic Press Limited, London.

[31] Richards, J. P., "Lineaments Revisited", SEG newsletter, $42,14-21,2000$.

[32] Rowan. L. C. and Lathram. E. H.: "Mineral Exploration", in Remote Sensing in Geology (B. S. Siegal and A. R. Gillespie, editors), John Wiley and sons, NY. 553-605, 1980

[33] Sabins, F. F.: Remote Sensing: Principles and Interpretation. W. H. Freeman and Company, New York, 361. 1997

[34] Sabins, F., Remote Sensing: Principles and interpretation, 2nd edn (New York, NY: Freeman), 1997.

[35] Saied Pirasteh, Biswajeet Pradhan, Hojjat O. Safari, Mohammad Firuz Ramli: "Coupling of DEM and remote-sensing-based approaches for semi-automated detection of regional geostructural features in Zagros mountain, Iran", Arab J Geosci 6:91-99, 2013

[36] Stefouli, Angellopoulos. A. Perantonis. S., Vassilas. N.. Ambazis. N. and Charou.E.: "Integrated Analysis and Use of Remotely Sensed Data for the Seismic Risk assessment of the southwest Pelopones sus Greece", First Congress of the Balkan Geophysical Society, 23-27 September, Athens Greece. 1996

[37] Stephen Rippington, Dickson Cunningham , Richard England, Bart Hendriks: "The crustal assembly of southern Mongolia: New structural, lithological and geochronological data from the Nemegt and Altan ranges", Gondwana Research 23: 1535-1553, 2013

[38] Suzen, M. L., Toprak, V., "Filtering of satellite images in geological lineament analyses: an application to a fault zone in Central Turkey", International Journal of Remote Sensing, 19, 1101-1114, 1998.

[39] Toulouse, France, 21-25 July 2003, Volume IV, p. 2964 2966, 2003

[40] Woodall, R., "Empiricism and concept in successful mineral exploration", Australian Journal of Earth Sciences 41(1): 1-10, 1994

[41] Woodall, R., "The multidisciplanary team approach to successful mineral exploration", Society of Economic Geologists Newsletter 14: 1-6, 1993.

[42] Zakir, F., Qari, M., Mostfa, M., "A new optimising technique for preparing lineament density maps", International,Journal of Remote Sensing, 20, 1073-1085, 1999 


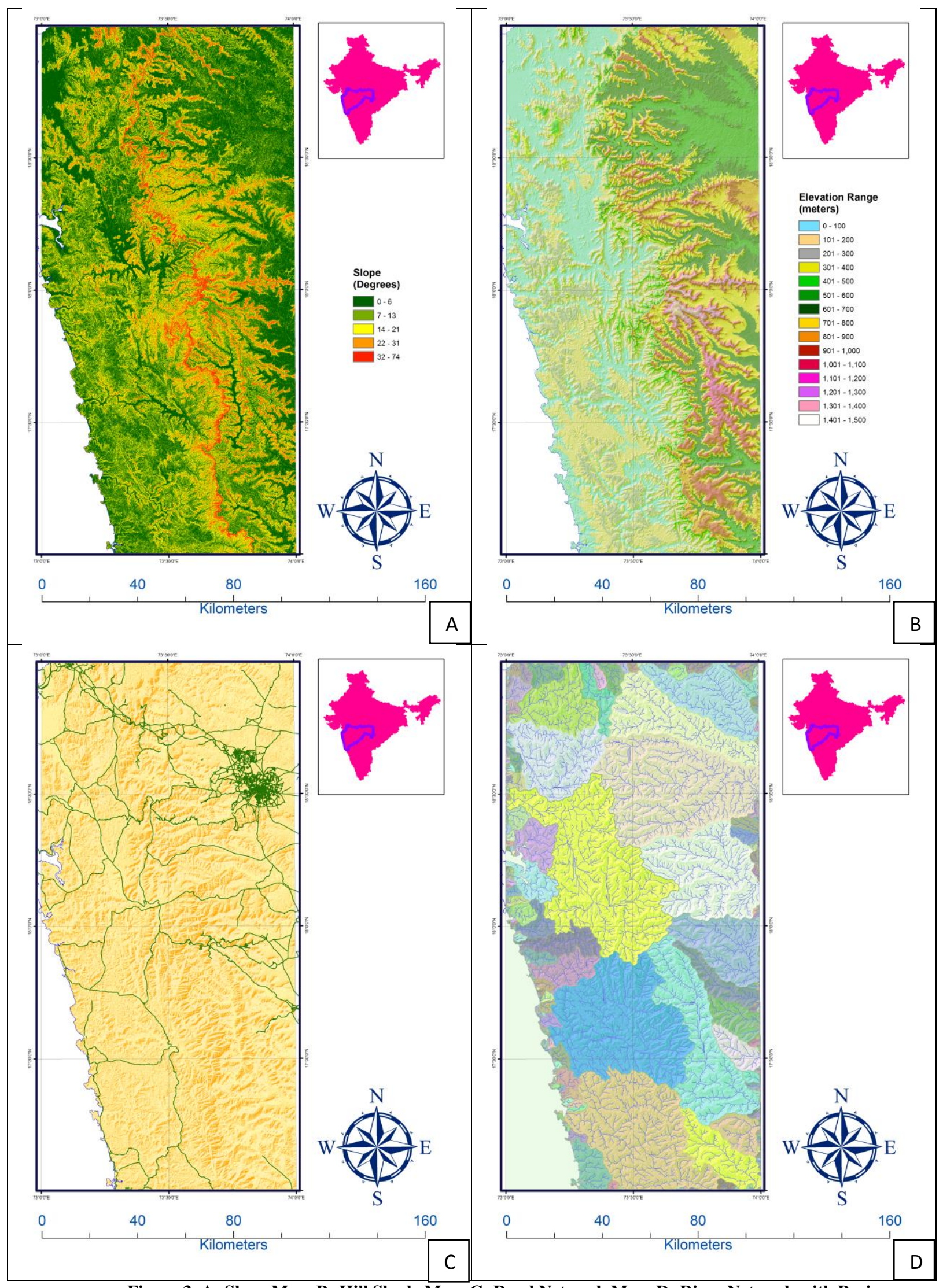

Figure 3. A: Slope Map, B: Hill Shade Map, C: Road Network Map, D: River Network with Basins 


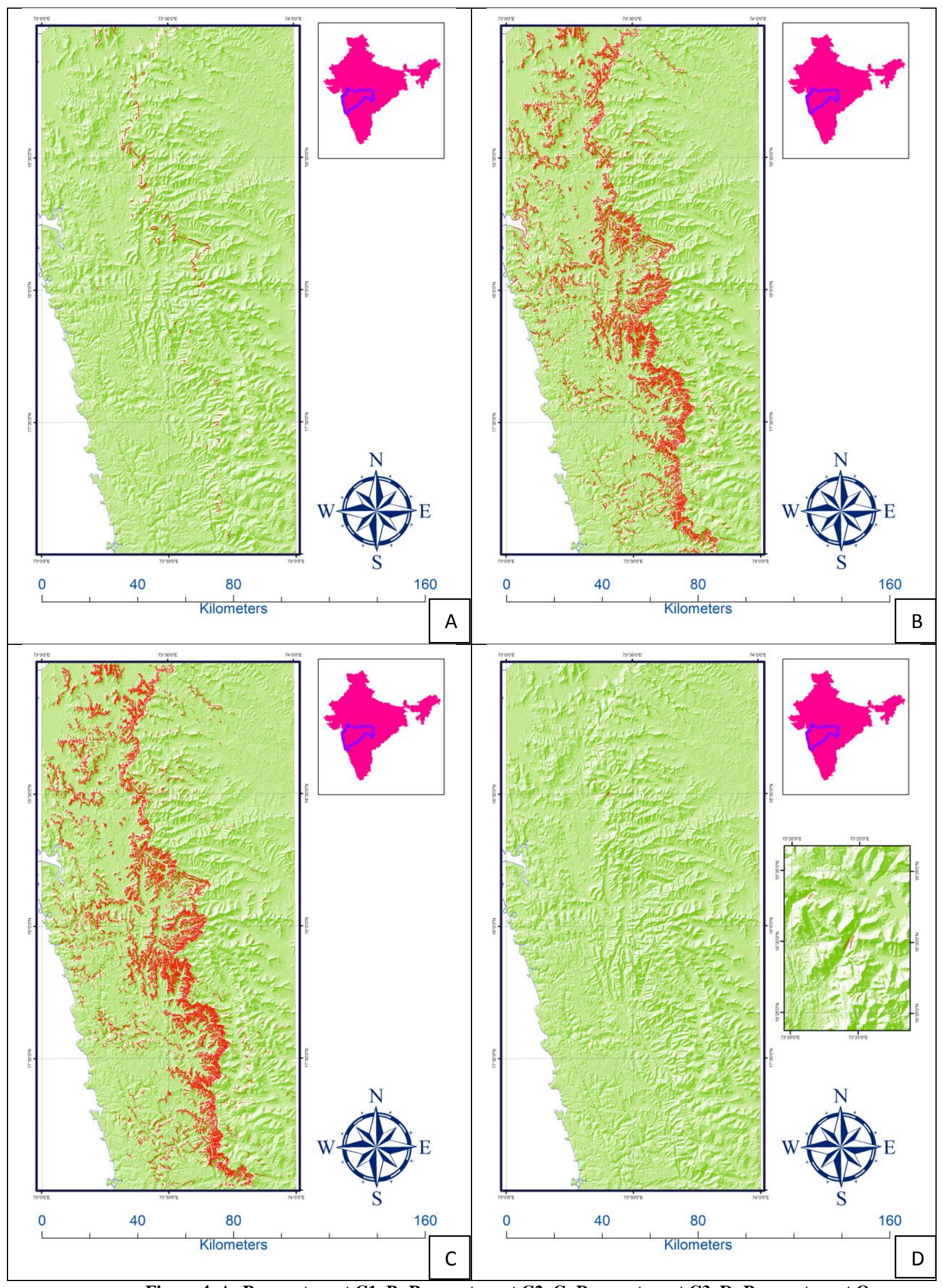

Figure 4. A: Parameter set C1, B: Parameter set C2, C: Parameter set C3, D: Parameter set O 


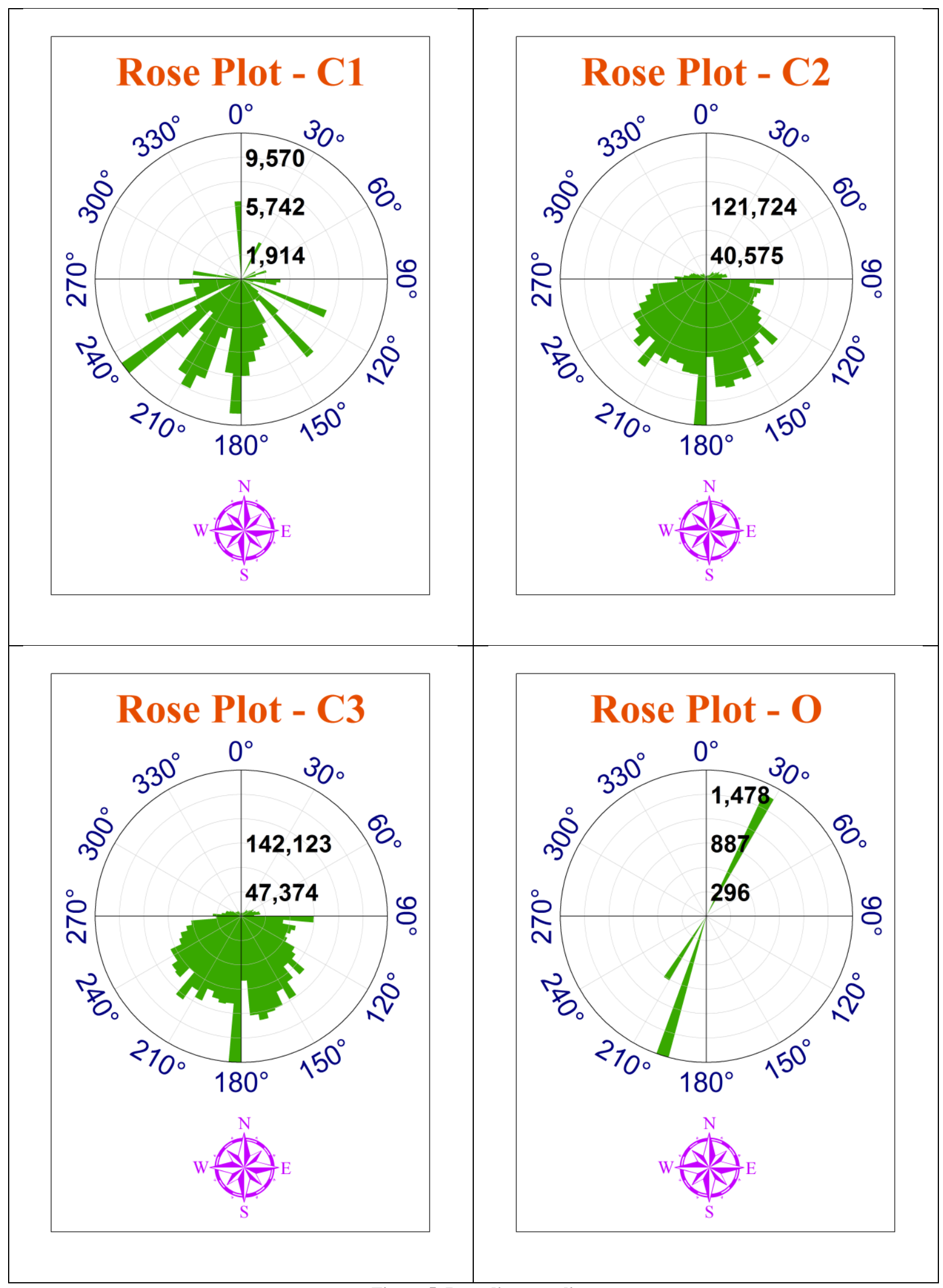

Figure 5. Rose diagrams lineaments 


\section{AUTHOR'S PROFILE}

A. D. Prasad received B. Tech from Andhra University, M. Tech. from National Institute of Technology Karnataka. He worked as Asst. Environmental Engineer in the initial days of the career and afterwards shifted to IT sector, worked in the domain SAP - BI / SEM / IP and performed various roles as team member, technical leader, lead consultant, project manager and competency head. He worked at various capacities in India, USA, UAE, Saudi Arabia, Qatar, Malaysia, UK and South Africa before joining as a research scholar at Indian Institute of Technology Roorkee, India. He is also delivering lectures at various universities. His research interests include Energy, Renewable Energy, GIS, HAZOP, Hazards and Mitigation, Impact Analysis, SAP-GIS and Medical Image Processing. He is a life member of IGS (India). 